\title{
Optimization of Drilling of Carbon Fiber Reinforced Polymer with the Grey-Based Method
}

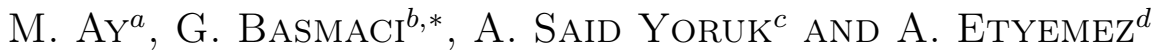 \\ ${ }^{a}$ Marmara University, Faculty of Technology \\ ${ }^{b}$ Mehmet Akif Ersoy University, Faculty of Engineering and Architecture, Burdur, Turkey \\ ${ }^{c}$ Technical Science Vocational School, Iğdır University, Iğdır, Turkey \\ ${ }^{d}$ Nikken, Turkey
}

\begin{abstract}
The present study investigates the effect of cutting speed, feed rate, and drill diameter on thrust force, delamination factor, surface quality, and drill wear in drilling carbon fiber reinforced polymer composite (CFRP). The drilling tests are conducted with solid carbide drills cutting tools. In order to determine the optimum cutting conditions, the Taguchi method is used in the experimental design. The Grey relational analysis is used to optimize the drilling parameters of these composites. To minimize the compressive forces that occur during drilling, as a result of the Grey relational analysis, 0.075 feed, $4 \mathrm{~mm}$ drill diameter, and $50 \mathrm{~mm} / \mathrm{min}$ cutting speed parameters appear to be efficient.
\end{abstract}

DOI: 10.12693/APhysPolA.137.535

PACS/topics: carbon fiber reinforced polymer composites, drilling, Taguchi method, Grey relational analysis

\section{Introduction}

Due to display of high strength in proportion to its weight, demand of carbon fiber reinforced polymer is increasing in aviation and automotive industries. This engineering material, besides its lightness, is preferred in various applications also because of its resistance to high corrosion and fatigue strength [1,2].

Notably, in aviation and automotive industries, usage of composite materials is increasing in several sectors, due to factors such as usage rate, lightness, and durability. Especially due to increase in size, flight time, and affordability, aircrafts are expected to be manufactured as light as possible [1]. Composites used in aviation and automotive industries are mostly manufactured from carbon fiber reinforced epoxide or vinyl ester (CFRP). CFRP composites are commonly used due to their perfect mechanical properties such as high specific hardness, high strength, high resistance to corrosion, and low thermal strain in comparison to metallic materials $[2,3]$.

Processing of fiber reinforced plastic composites is an important production phase in aviation and automotive industries. Conventional milling, turning, perforation, and grinding methods are all frequently used manufacturing methods for shaping the piece as desired [3]. Bolt and pin holes are required to be drilled for assembly of pieces manufactured from composites, and the assembly quality substantially depends on the quality of the hole. That is why composite pieces are required to be drilled precisely for high efficiency $[4,5]$. Aside from that, it is quite difficult to process pieces that are manufactured from CFRP - which are heterogeneous and

*corresponding author; e-mail: gbasmaci@mehmetakif.edu.tr anisotropic - without causing damages such as delamination, fiber pull-out, and surface burning [3]. Drilling operations have great importance in both aviation and automotive industries [6].

Mechanical properties of fiber reinforced polymer composite laminates generally vary by position and amount of fiber in polymer matrix. Especially bidirectional fiber reinforced laminate composites possess maximum hardness and strength along both directions [3]. In addition, heterogeneous characteristic and anisotropic structure of CFRP composites cause the occurrence of overheating, high shearing force, tool wear, ripping of fibers from the matrix, delamination, and unwanted surface qualities during the process [6]. On the other hand, hightemperature and chip formation in powder form that occur during the drilling process cause deterioration in the surface integrity of anisotropic and nonhomogeneous CFRP laminates [7]. This situation is due to divergence of mechanical and thermal features of reinforcement materials and matrix that form the composite material [8]. There is still not a clear understanding of reasons for breaking types of fiber and matrix that occur due to shearing force during drilling [9]. Especially for CFRP composite, improperly selected drilling conditions during drilling processes affect hole quality (hole diameter, surface roughness, hole damage, etc.) negatively, and increase formation of delamination. Therefore, studies on drillability of CFRP composite materials are mostly about delamination and surface roughness depending on compressive force and torque values [10, 11]. Zitoune et al., as well as Ghafarizadehl et al. [12] has analyzed the effects of cutting parameters on tool wear, surface roughness, chip formation, hole quality, and cylindricality in the drilling of KFTK/A1 material stock using WC cutting tools with or without coating. It has been observed that coated tools present better hole quality 
than uncoated tools. As for compressive force, a decrease at the rate of $47 \%$ for aluminum plates and $20-25 \%$ for CFRP plates have been observed. Merino-Perez et al. have examined the effects of cutting speed and material specifications on heat distribution during drilling of CFRP materials with uncoated cutting tools. They have indicated that carbon fiber reinforcement rate and type are key parameters for the heat generated during drilling of CFRP materials. In analyses made with SEM, they have determined that high cutting speeds cause more deterioration in entry-exit of holes and severe matrix fractions [13-16].

In this study, the drillability performance of carbon fiber reinforced polymeric composite material using different cutting parameters under dry and cryogenic conditions has been investigated. In the experimental study two different cutting speeds (20 and $50 \mathrm{~mm} / \mathrm{min}$ ), three different feeds $(0.075,0.15$, and $0.225 \mathrm{~mm} / \mathrm{rpm})$, and two different drill diameters (4 and $6 \mathrm{~mm}$ ) have been used. To minimize the compressive forces that occur during drilling, as a result of Grey relational analysis, 0.075 feed, $4 \mathrm{~mm}$ drill diameter, and $50 \mathrm{~mm} / \mathrm{min}$ cutting speed parameters appear to be efficient.

\section{Experimental study}

Drill diameter's effect on the compressive force in the drilling of carbon fiber reinforced composite materials with varying cutting parameters under dry and cryogenic conditions has been investigated experimentally. An experimental study has been executed in 3-axis CNC machining centers. Guhring brand drills with G1149 serial number, which were developed for drilling of composite materials, have been used in the experiments. At the time of the experiment, measurement of compressive force has been executed with Type 9257B Kistler dynamometer and ancillary equipment.

\subsection{Experimental design}

The experimental design was devised using the Taguchi method. Therefore, obtaining more comprehensive results from fewer experiments was possible. This way, time and money have been saved [17].
Measurement of compressive force during cutting phase with experimental studies is an important matter for manufacturing. The principle of the least is the best was utilized in order to keep compressive force values low in the drilling of composite materials.

The formulation that was used in calculating $S / N$ ratio in accordance with the least is the best principal, is given as:

$$
S / N=-10 \log \left(\frac{1}{n} \sum_{i=1}^{n} y_{i^{2}}\right),
$$

where $n$ represents the number of experiments under test conditions, and $y$ represents measured characteristic.

Processing parameters and levels that were used in the experiment are presented in Table I.

TABLE I

Processing parameters and levels used in the experiment.

\begin{tabular}{c|c|c|c}
\hline \hline Level & $\begin{array}{c}\text { Feed } \\
{[\mathrm{mm} / \mathrm{rpm}]}\end{array}$ & $\begin{array}{c}\text { Drill diameter } \\
{[\mathrm{mm}]}\end{array}$ & $\begin{array}{c}\text { Cutting speed } \\
{[\mathrm{mm} / \mathrm{min}]}\end{array}$ \\
\hline 1 & 0.075 & 4 & 20 \\
2 & 0.15 & 6 & 50 \\
3 & 0.225 & &
\end{tabular}

Considering the factors and levels in Table I, the Taguchi $\mathrm{L}_{8}$ orthogonal sequence with 8 tests was selected as the most appropriate design for the experimental study. $\mathrm{L}_{8}$ experimental design that was determined with help from Minitab 17 statistics software can be seen in Table II.

\subsection{Taguchi based Grey relational analysis method}

The obtained experimental results and the determined parameters were optimized with the Grey based Taguchi method. Using regression model, researches were carried out calculating an equation between dependent parameters and independent parameters. The Taguchi method uses a special design of orthogonal arrays to study the entire parameter space with a small number of experiments only.

Taguchi $\mathrm{L}_{8}$ experimental design and compressive forces.

TABLE II

\begin{tabular}{c|c|c|c|c|c|c}
\hline \hline Exper. No. & Variables & $\begin{array}{c}(\mathrm{A}) \text { Feed } \\
{[\mathrm{mm} / \mathrm{rpm}]}\end{array}$ & $\begin{array}{c}(\mathrm{B}) \text { Drill } \\
\text { diameter }[\mathrm{mm}]\end{array}$ & $\begin{array}{c}(\mathrm{C}) \text { Cutting } \\
\text { speed }[\mathrm{mm} / \mathrm{min}]\end{array}$ & $\begin{array}{c}\text { Dry cutting } \\
\text { force }[\mathrm{N}]\end{array}$ & $\begin{array}{c}\text { Cryogenic cutting } \\
\text { force [N] }\end{array}$ \\
\hline 1 & $\mathrm{~A}_{1} \mathrm{~B}_{1} \mathrm{C}_{1}$ & 0.075 & 4 & 20 & 50.2 & 77.39 \\
2 & $\mathrm{~A}_{1} \mathrm{~B}_{2} \mathrm{C}_{2}$ & 0.075 & 6 & 50 & 42.57 & 146.2 \\
3 & $\mathrm{~A}_{2} \mathrm{~B}_{1} \mathrm{C}_{1}$ & 0.15 & 4 & 20 & 65.07 & 112.9 \\
4 & $\mathrm{~A}_{2} \mathrm{~B}_{2} \mathrm{C}_{2}$ & 0.15 & 6 & 50 & 87.7 & 207.1 \\
5 & $\mathrm{~A}_{3} \mathrm{~B}_{1} \mathrm{C}_{2}$ & 0.225 & 4 & 50 & 66.11 & 109 \\
6 & $\mathrm{~A}_{3} \mathrm{~B}_{2} \mathrm{C}_{1}$ & 0.225 & 6 & 20 & 98.19 & 221.9 \\
7 & $\mathrm{~A}_{4} \mathrm{~B}_{1} \mathrm{C}_{2}$ & 0.3 & 4 & 50 & 78.45 & 134.8 \\
8 & $\mathrm{~A}_{4} \mathrm{~B}_{2} \mathrm{C}_{1}$ & 0.3 & 6 & 20 & 119.4 & 257.1
\end{tabular}


The experimental design was done using the Taguchi method. Hence, it has been possible to reach more comprehensive results with less experiment. In this sense, time and money have been used more efficiently [17, 18]. While only one outcome is optimized in the Taguchi method, multiple outcomes can be optimized in a Grey relational analysis [19]. In this study, the Taguchi method was used in the experimental design step and the Grey relational analysis method was used in the optimization step.

The Grey relational analysis optimization process was carried out in the following four steps [19]: (i) Normalization of experimental results (the lowest-the best), (ii) Calculation the Grey relational coefficient, (iii) Calculation of the Grey relational degree, (iv) Determination of optimal experiment parameters.

In the normalization step, the experimental results were normalized using the equation below according to principle of the lowest-the best:

$$
x_{i}(k)=\frac{\max \left(y_{i}(k)\right)-y_{i}(k)}{\max \left(y_{i}(k)-\min \left(y_{i}(k)\right)\right.},
$$

where $x_{i}(k)$ refers to the value at the $i$ series and $k$ row after normalization process, $\min \left(y_{i}(k)\right)$ refers to the minimum value at the $i$ series, $\max \left(y_{i}(k)\right)$ refers to the maximum value at the $i$ series, and $y_{i}(k)$ refers to the original value at the $i$ series and $k$ row.

In step (ii), the Grey relational coefficient was calculated via:

$$
\xi_{i}(k)=\frac{\Delta_{\min }+\zeta \Delta_{\max }}{\Delta 0_{i}(k)+\zeta \Delta_{\max }} .
$$

Here, $\zeta$ is a distinguishing coefficient between 0 and 1 , $\Delta 0_{i}$ is the amount of deviation between the reference series and the normalization values, $\Delta_{\text {min }}$ refers to the minimum value of the deviation sequence from the reference series, and $\Delta_{\max }$ refers to the maximum value of deviation sequence from the reference series.

In step (iii), the Grey relational degree was calculated using

$$
\gamma_{i}=\frac{1}{n} \sum_{k=1}^{n} \xi_{i}(k) .
$$

\section{Experimental results and discussion}

\subsection{Optimization of experimental results for surface roughness and cutting force}

In the experimental step, the Taguchi $\mathrm{L}_{8}$ experiment design, surface roughness, and cutting force values were shown in Table II. The Grey relational analysis method was applied to the experimental results shown in Table III, together with the results from the other steps (normalization, delta values, and the Grey relational grade). The Grey relational coefficients were calculated with (3), and are shown in Table III.
TABLE III

Normalized data, delta values, and grey relational grade for conventional insert tool obtained for each experiment number.

\begin{tabular}{c|c|c|c|c|c|c}
\hline \hline \multirow{2}{*}{ No. } & \multicolumn{2}{|c|}{ Normal. data } & \multicolumn{2}{c|}{ Delta values } & \multicolumn{2}{c}{ Grey rel. grade } \\
\cline { 2 - 7 } & $\begin{array}{c}\text { Dry } \\
{[\mathrm{N}]}\end{array}$ & $\begin{array}{c}\text { Cryogenic } \\
{[\mathrm{N}]}\end{array}$ & $\begin{array}{c}\text { Dry } \\
{[\mathrm{N}]}\end{array}$ & $\begin{array}{c}\text { Cryogenic } \\
{[\mathrm{N}]}\end{array}$ & $\begin{array}{c}\text { GRA } \\
\text { values }\end{array}$ & $\begin{array}{c}\text { GRA } \\
\text { rank }\end{array}$ \\
\hline 1 & 0.099 & 0.000 & 0.834 & 1.000 & 0.917 & 1 \\
2 & 0.000 & 0.383 & 1.000 & 0.566 & 0.783 & 2 \\
3 & 0.293 & 0.198 & 0.631 & 0.717 & 0.674 & 4 \\
4 & 0.587 & 0.722 & 0.460 & 0.409 & 0.435 & 6 \\
5 & 0.306 & 0.176 & 0.620 & 0.740 & 0.680 & 3 \\
6 & 0.724 & 0.804 & 0.409 & 0.383 & 0.396 & 7 \\
7 & 0.467 & 0.319 & 0.517 & 0.610 & 0.564 & 5 \\
8 & 1.000 & 1.000 & 0.333 & 0.333 & 0.333 & 8
\end{tabular}

TABLE IV

Grey relational degrees of the factor levels for drilling.

\begin{tabular}{c|c|c|c}
\hline \hline Levels & $\begin{array}{c}\text { (A) Feed } \\
{[\mathrm{mm} / \mathrm{rpm}]}\end{array}$ & $\begin{array}{c}\text { (B) Diameter } \\
{[\mathrm{mm}]}\end{array}$ & $\begin{array}{c}\text { (C) Spindle speed } \\
{[\mathrm{m} / \mathrm{min}]}\end{array}$ \\
\hline 1 & $\underline{0.791}$ & $\underline{0.638}$ & 0.549 \\
2 & 0.503 & 0.599 & 0.609 \\
3 & 0.448 & 0.535 & $\underline{0.639}$
\end{tabular}

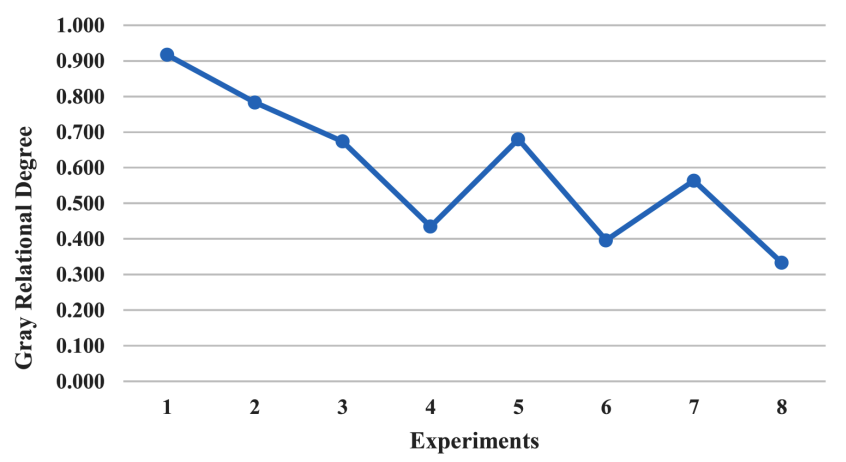

Fig. 1. Grey relational degrees for each experiment.

The Grey relational degrees related to each experiment result were calculated and the results of the experiment were ranked in order from highest Grey relational degree to present in Tables III and IV.

As seen from Table IV, A1 (feed $0.075 \mathrm{~mm} / \mathrm{rpm}$ ), B3 (diameter $4 \mathrm{~mm}$ ), and C1 (spindle speed $50 \mathrm{~mm} / \mathrm{min}$ ) were selected as the optimal parameter levels on the results. The optimal parameters levels will represent the lowest surface roughness and cutting force value.

The Grey relational degrees related to each experiment result were calculated and the results of the experiment were ranked in order from the highest Grey relational degree to present in Table IV and Fig. 1. 


\section{Conclusions}

In this study, the drillability performance of carbon fiber reinforced polymeric composite material using different cutting parameters under dry and cryogenic conditions has been investigated. In the experimental study, two different cutting speeds (20 and $50 \mathrm{~mm} / \mathrm{min}$ ), three different feeds $(0.075,0.15$, and $0.225 \mathrm{~mm} / \mathrm{rpm})$, and two different drill diameters ( 4 and $6 \mathrm{~mm}$ ) have been used. At the time of experimental work, compressive forces were displayed online. The results obtained from the study are presented below.

In the drilling of the carbon fiber reinforced polymeric composite material, force generated under cryogenic conditions was approximately twice the force generated under dry cutting conditions. The reason for more force generation under cryogenic conditions is the increase in material's Young's modulus and tensile stress when exposed to extreme cold. With the increasing tensile stress, material transforms into a hard and fragile structure. Therefore, the metal removal operation becomes difficult.

To minimize the compressive forces that occur during drilling, as a result of the Grey relational analysis, 0.075 feed, $4 \mathrm{~mm}$ drill diameter, and $50 \mathrm{~mm} / \mathrm{min}$ cutting speed parameters appear to be efficient.

\section{References}

[1] R.M. Sauter, R.V. Lenth, Experimental Design for Process Settings in Aircraft Manufacturing, in: Statistical Case Studies. A Collaboration between Academe and Industry, Eds R. Peck, L.D. Haugh, A. Goodman, Society for Industrial and Applied Mathematics, 1998, p. 235.

[2] I. El-Sonbaty, U.A. Khashaba, T. Machaly, Compos. Struct. 63, 329 (2004).
[3] E. Brinksmeier, S. Fangmann, R. Rentsch, CIRP Ann. Manufact. Technol. 60, 57 (2011).

[4] A. Faraz, D. Biermann, K. Weinert, Int. J. Machine Tools Manufact. 49, 1185 (2009).

[5] K. Giasin, S. Ayvar-Soberanis, A. Hodzic, J. Clean Prod. 135, 533 (2016).

[6] K. Giasin, S. Ayvar-Soberanis, A. Hodzic, Mater. Des. 89, 996 (2016).

[7] M.A. Herbert, D. Shetty, G. Vijay, R. Shetty, Europ. Sci. J. 10, 279 (2014).

[8] U.A. Khashaba, I.A. El-Sonbaty, A.I. Selmy, A. Megahed, Composites A 41, 391 (2010).

[9] M. Lazar, P. Xirouchakis, Int. J. Machine Tools Manufact. 51, 937 (2011).

[10] K. Palanikumar, T. Srinivasan, K. Rajagopal, B. Latha, Mater. Manufact. Process 31, 581 (2016).

[11] R. Zitoune, M. El, V. Krishnaraj, Wear 302, 156 (2013).

[12] S. Ghafarizadehl, G. Lebrun Jean, F. Chatelain, J. Compos. Mater. 50, 8 (2016).

[13] K. Shunmugesh, K. Panneerselvam, Eng. Sci. Technol. Int. J. 19, 1552 (2016).

[14] T. Srinivasan, K. Palanikumar, K. Rajagopal, B. Latha, Mater. Manufact. Process 32, 226 (2017).

[15] I. Wstawska, K. Slimaka, Arch. Mech. Technol. Mater. 36, 12 (2016).

[16] T. Xia, Y. Kaynak, C. Arvin, I.S. Jawahir, Int. J. Adv. Manufact. Technol. 82, 60 (2016).

[17] M. Ay, Acta Phys. Pol. A 131, 349 (2017)

[18] G. Basmac1, M. Ay, Acta Phys. Pol. A 131, 354 (2017).

[19] M. Ay, Y. Altunpak, S. Hartomacığlu, Acta Phys. Pol. A 131, 551 (2017). 